\title{
First You Stand out, then You Stand up: Becoming an Ally for the LGBT Community
}

\author{
Manpreet Dhillon, Jerome Rabow, Jennifer Moore, Yvette Meza Vega \\ University of California, Los Angeles, USA \\ Email: dhillonm28@gmail.com,jrabow@soc.ucla.edu, jen.monica.moore@gmail.co,myvette@ucla.edu,
}

Received July 21 ${ }^{\text {st }}$, 2013; revised August 30 ${ }^{\text {th }}$, 2013; accepted September $12^{\text {th }}, 2013$

\begin{abstract}
Copyright (C) 2013 Manpreet Dhillon et al. This is an open access article distributed under the Creative Commons Attribution License, which permits unrestricted use, distribution, and reproduction in any medium, provided the original work is properly cited.
\end{abstract}

\begin{abstract}
This paper addresses one of the ways that counselors and teachers in schools can address the homoprejudices and homophobia that many of their heterosexual students have towards the LGBT community. We describe a classroom exercise that allows heterosexual students to achieve understanding and empathy and stand up for the Lesbian, Gay, Bisexual and Transsexual (LGBT) community. This exercise was administered to university students in an upper division course who were given the choice of volunteering to wear a Pink Triangle pin for one week. The Pink Triangle, originally worn by gays during the World War two Holocaust, has become a symbol of gay liberation. The students recorded their experiences and feelings throughout the course of their pin-wearing. Results for this blue-collar, mostly female and non-white population, indicate key shifts in understanding oppressions that queer youth face every day. In addition to their increased awareness, students committed to become allies by taking action to fight for social justice. A description of the educational assignment is provided so that counselors, teachers, and other educators can elect to increase the understanding of their heterosexual students and to create a safe space for the dialogue between all students, regardless of their identities.
\end{abstract}

Keywords: LGBT Community; Homophobia; Pink Triangle; Social Justice

\section{Introduction}

Americans, who are believers and advocates of gay marriage, await with hope, that the upcoming Supreme Court decision in June of 2013 will support the legitimacy of gay marriage. However, those who have been on the ground struggling with day-to-day discrimination and bullying, know that, even with new legislation, harassment, invectives, slurs, and bashing of the LGBT community will continue. Inspite of the "inevitability" of widespread acceptance of gay marriage by the majority of our citizenry (Klarman, 2012), this paper argues that it is the day-to-day interactions that need to be addressed for homophobia and oppression to be reduced. While legislation is important, it is equally important to change the hearts and minds of individuals.

In this paper, we propose the use of the Pink Triangle as a way to educate and recruit allies in the LGBT struggle for justice. It is our belief, based on the research cited here, that the use of this educational endeavor will increase awareness and understanding amongst heterosexual youth and will promote safe and inclusive environments for queer and transgender youth by reducing homophobia and oppression. Discrimination of LGBT youth varies over the life cycle, but also faces rejection and isolation from their parents and peers. In one survey of young males, only 12 percent felt confident they could befriend a gay person (Marsiglio, 1993), while a more recent survey reported that $75 \%$ of LGBT youth have experienced discrimination (Mays \& Cochran, 2001). Our paper specifically addresses how the rejection, isolation, and oppression received by LGBT youth can be transformed into understanding, empathy, and the development of allies. The paper is recommended to all high school as well as college educators.

\section{Background}

The Pink Triangle was first used by Nazi Germany to identify homosexuals in concentration camps during the Holocaust. Just as the yellow Star of David was used to mark Jewish prisoners (and non-prisoners), the pink triangle was used to mark homosexuals and sex offenders. Gay individuals were deemed as "undesirable" by the Nazis, along with Jews, Roma, people of color, the disabled, and other non-Christian minorities. Labeling prisoners in concentration camps through different colored symbols allowed the Nazis to create a hierarchy where homosexuals ranked the lowest, just below the Jews. They received the worst treatment and were often beaten, tortured, and killed in brutal manners. Even after liberation of the camps, homosexual acts and relations were punishable crimes. Homosexual men were viewed as a threat because they would reduce the capacity to wage war and purify the German race ${ }^{1}$.

The Pink Triangle was reclaimed in the 1970 s by gay liberation groups to draw attention to the oppression and persecution of the LGBT community. The symbol gained popularity in the 1980s when the AIDS advocacy organization, ACT UP, used it as a symbol to raise awareness about the AIDS epidemic. Their

\footnotetext{
${ }^{1}$ For more information on the use of different colored triangles used by the Germans to identify prisoners see
}

http://www.geneseo.edu/safe_zone/triangle_history. 
campaign included a picture of the inverted pink triangle and the slogan "Silence = Death", . The organization drew comparisons between the brutal death sentences issued by the Nazis to the silencing of information about AIDS/HIV by the government that caused thousands of deaths. The Pink Triangle is now embraced by the LGBT community as a symbol of political consciousness and historical memory of the Nazi persecution of gays and lesbians. The symbol has mobilized and raised awareness against contemporary oppression of the LGBT community (Jensen, 2002).

The Pink Triangle exercise was first used by Chesler and Zuniga (1991) in a classroom as a way of teaching students how to resolve conflict by wearing the pin for a period of 24 hours.

Rabow, Stein and Conley (1999) asked students to volunteer wearing the pin for one week. In papers analyzed according to Helm's (1990) theory of identity and Goffman's (1964) work on stigma students advanced through different stages of identity development and moved toward more open and positive ways of thinking about their LGBT peers and community. Milman and Rabow (2006) extended the period to five weeks of pinwearing and reported that the longer the pin wearing, the greater the impact on the "self" and on the understanding of gays and lesbians. This paper uses the same methodology (Rabow, Stein, \& Conley, 1999; Milman \& Rabow, 2006) but is done with a radically different sample.

We first describe the educational effort and then more fully in the Appendix, provide directions on how to administer the triangle to your classes or campus and account for those who elect not to wear the pin.

\section{Methods}

\section{Participants}

19 students $(\mathrm{F}=16, \mathrm{M}=3$ ) out of 21 in an upper division course at a public university wore the pink triangle for one week. The sample consisted of a very small percentage of White students, was mostly blue collar Latina/os seniors who strongly identified as being religious, specifically Catholic. The age range was from 19 to 23 years with one older female age 50 and male age 41 . These students, as well as the two who elected not to wear the pin, received extra credit for writing a paper on their experience with the pin.

\section{Materials}

The triangle that students wore was made of pink Styrofoam with a rainbow ribbon glued across it to insure that people would see the triangle as a symbol of gay rights. These were homemade by the instructors prior to the class.

\section{Procedure}

Students were presented with the option of wearing a Pink Triangle pin for the length of one week. Assigned as an extra credit assignment, students were asked to record their daily experiences and feelings while wearing the pin. Students who elected not to wear the pin were also given the opportunity to receive extra credit by recording how they felt not participating in the assignment. To receive extra credit, students were re-

\footnotetext{
${ }^{2}$ A documentary, "How to Survive a Plague" focuses on the use of the Pink Triangle as a symbol to raise awareness about the AIDS/HIV epidemic.
}

quired to write a final paper which asked them to address their experiences with pin-wearing (see Appendix I for more details). The papers were analyzed according to a set of categories developed from reading of their work which we have classified into four categories: choice of wearing or non-wearing, what the students learned about themselves, how they came to understand what a safe and inclusive environment means for LGBT youth, and finally their commitments to social action that would achieve social justice for the LGBT community.

\section{Electing to Wear the Pin}

Most of the students were hesitant, anxious and fearful about pin-wearing, being concerned with family, friends and coworkers. While all students, except one, elected to wear the pin, pin-wearers did not wear this pin all day long and made decisions of when and in front of whom to wear the pin. A heterosexual female expressed her apprehension as follows:

\begin{abstract}
"Because I am in such close quarters with children and their parents I chose not to wear the pink triangle. I did not want to have to answer any questions or offend anyone. Thinking back now I wish I would have worn it. I realized that my agency may not have cared. They pride themselves on being non-discriminating. I decided to not wear the pin because it scared me to look at it on myself. I was fearful of other people's reactions."
\end{abstract}

Unsure of how family members would react to this symbol of equality, some students opted to not wear the pin at home, while others stepped up to the challenge even though they knew the pin might cause disagreements. A Latina female student describes her experience of wearing the pin to pick up her parents from the airport.

"My parents didn't say anything about the pin until they started noticing how people were just staring at me. People would look at me with disgust. I could feel the eyes on me, and the sad thing was that they were looking at me like I was a piece of $\mathrm{S}^{* * *}$. My family noticed how people were looking at me and my dad said very angrily, 'Take that $\mathrm{sh}^{* * *}$ off!' My little brother asked me why I was wearing the pin and I told him I would explain to him when he was older. I didn't want to take it off at first but the worried and disappointed looks on my parents' faces made me feel bad. My parent's reactions hurt more than the public's reactions. It was there at the airport when I thought about how horrible gay people feel when the public stares at you like you are a piece of $\mathrm{sh}^{* * *}$.

Please excuse my language but that is how I can best describe how I felt.”

The Latina student later tried explaining the meaning behind the Pink Triangle to her parents and why she was wearing it. Her father simply shut her out every time she tried talking to him about it. She was unable to resolve these issues with her father.

“To this day my dad hasn't spoken to me and this really hurts me because I am trying to do something good but my dad doesn't realize it and doesn't want to accept it. My parents and boyfriend mean a lot to me so their reactions had a tremendous impact on me emotionally. The people that matter the most to me did not support or agree 
with my decisions which hurt me the most. I feel emotionally drained."

Electing to wear the pin was not only a difficult decision for heterosexual students but also for the lesbian student in our class. This Latina student did not reveal her sexual orientation until the pin wearing began and described her experience as, "I must admit that wearing the pink triangle had its bittersweet moments. At times I felt extremely proud but at other times I wanted to find a corner and hide.”

\section{What They Learned about Themselves and Others}

There was self-learning and learning about others through pin-wearing. Sometimes one dimension was more important than the other. In the following excerpt, an Iranian male, indicates his understanding of the burdens placed upon the gay community.

“The pink triangle experience showed me the burden society places on gay women and men and the thick skin you must wear to protect yourself... I felt alone and helpless, constantly keeping my guard up in order to fight off any unwanted attention. There would be so many instances where I could feel the actual weight of the pin, becoming heavier and heavier as the judging eyes multiplied”.

In this second excerpt, a student, despite her fears, discovers that by standing up to her manager, she now sees herself differently.

"That day after work I was really proud of myself for wearing the pin to work, I felt like I had accomplished something by standing up for what I believe in. It was hard to hear what my manager and co-worker had to say about homosexuals but it made me realize that gay people don't have it easy and I can now somehow understand how hard it might be for them to come out. I felt that he [manager] saw me differently because I supported a cause he is against... I have now gained so much more respect for the LGBT community and I have now felt their pain and their struggles."

Negative experiences also occurred in public arenas. A Latina female goes to In-N-Out, a fast food restaurant, with her boyfriend. She comes to recognize the privilege of heterosexuality.

"Upon arriving I noticed a lot of people staring at me including employees. Their eyes went immediately to the pin and then to my face. I could tell that they were questioning whether I was a supporter of gay rights or whether I was myself gay. Their expressions became even more puzzled when my boyfriend approached me after leaving the bathroom. He walked over and gave me a kiss. At this exact moment I saw one of the employees stop what he was doing with the fries to look over at me. His eyes got bigger and his mouth dropped. My boyfriend asked, 'Why is everyone staring at you?' I answered 'I don't know. Let's go elsewhere to eat'. This incident showed me how I really am part of a dominant group. I always took for granted being able kiss or hold hands with my boyfriend in public".

In this next excerpt, a Latina student discovers the important role of silence in perpetuating discrimination and she loses her fear of speaking out.

“This experience was a test for me. Was I willing to support something which might receive resistance? It's so easy to be that person that supports a cause silently. But it's not easy to support something out loud because you leave yourself vulnerable to getting hurt...now after wearing the pin I know that I don't care if others think I'm gay."

In this final excerpt, a male who had looked up to and admired his grandmother is crushed when his grandmother expresses disdain for his pin wearing. The student captures the adulation for his grandmother that he felt as a youngster and the challenge of questioning adult authority.

"It shattered me to see someone [grandmother] I looked up to so fondly as a child demonstrate such ignorance. On one hand I felt broken, and on the other hand I felt an opportunity had presented itself, the opportunity to question the origin of my deepest roots. The most important lesson this experiment taught me was to question everything and to own the patterns in my life, to not simply adopt them but to create my own. I took pride in writing about this experience because its impact was far greater than anything I could have imagined...”

Awareness of the discrimination and suffering of others frequently moved students to think about how they could be involved in creating a safer and more inclusive environment.

\section{How They Create Safe and Inclusive Environments}

One pin-wearer opened up communication with her sister that had never existed before. "The most powerful moment I had with the pink triangle was talking openly with my sister about sexuality on the third day of wearing the pin. Prior to her seeing the triangle she knew that I supported the LGBT community, but I don't think she knew to what extent. When I asked her what she thought about my wearing the pink triangle, she was excited...She told me that she is attracted to both males and females with certain features. I was so happy that she told me this; she never expressed her attraction to females before...I value my relationship with my sister so much; to know a different part of her, a side of her that I've never known, just made me feel so wonderful on the inside. To think that this was made possible because of this class assignment, I just get emotional thinking about it...had I not worn it, I may not have known her sexuality."

A conversation one student had with her brother, after he came out to their family the night before, also creates closer sibling relations.

"My brother looked at me and he said, 'is that what I think it is?' I asked him, 'what do think this pin is saying?' He said to me, 'Do you support the gay community?' I said, yes. He wanted to cry and he gave me a hug. I was happy to see him react the way he did.”

A student whose uncle is gay, but was always ignored by the family, discovers that his pin wearing created closeness with one family member while pushing another one away. 
"My mother asked me about what the pink triangle...I was scared there would be a reaction that would not be gratifying. Regardless, I told my mom that it was a pin I had decided to wear because I wanted to support gay rights. My Uncle P [homosexual uncle] looked at me with smiling eyes that make me tear up when I think back upon it...My mom replied in Farsi with a puzzled face, 'That's sweet, since when?' I replied, 'Since always,'...my mom left for the bathroom soon after and it gave my Uncle a chance to speak freely without the tension of my mom's presence. He said to me, 'You have a good heart; my cousin (referring to my mom) raised a good man.' It meant the world to me and I knew it was only the beginning of my journey."

A Latina student counselor felt that she knew her counselee very well because she had been working with her counselee for two years discovered a new comfortable space for them to talk.

"She began to express that she was having a difficult time with her math class. I asked her if there was anybody that she knew that could help her with the class. She said, 'My ex-girlfriend can help me.' I was in complete shock not because she was bisexual or a lesbian, but the fact that she felt comfortable enough to express those words. I have never ever for the two years that I have worked as a counselor had students open up about their sexuality...I was happy that the pin spoke to the student on how I was on their (her?) side and with no judgment. I considered this moment the most memorable because I felt like I made an impact on a person to feel free to speak about their sexuality."

In another public space incident, pin wearing resulted in an employee expressing his appreciation for seeing an ally. While shopping at a makeup store, our student was asked about and explained what the Pink Triangle symbolized.

"By the time I was done explaining this to him, he had a huge smile on his face and his eyes were glimmering with unshed tears. He told me that he was gay and had just recently come out to his family. He said that throughout his entire life he had never seen someone walk around with their opinions blatantly pinned to their chest. He gave me a huge hug, and told me that people like me are very unique and definitely rare. He then went on to say that I had not only made his day, but also his year, because he felt like no one he knew in his life was fighting for equal rights as much as he was."

The inspiration that the employee felt for discovering that someone in his life was fighting for equal rights was also something that our students learned about pin-wearing.

\section{Standing up: Call to Action}

Many of our students strongly expressed the importance of speaking out. One student expressed her awareness as follows, "I know it's my duty as a person living in society to educate others, to stand up for those who can't stand up for themselves." Another student, a Filipino male, expressed his increased sense of responsibility for education in the struggle for equality.
“Our voices cannot be heard if we do not speak up. One does not have to be politically active, educationally affluent, or wealthy to pass knowledge about what is really going on in the world and our communities. This experience has shown me that a simple pin on your jacket can trigger great positive reactions from people but it can also trigger the most negative reactions, the important thing is that I was able to pull that trigger.”

\section{A Latina student reports a strong sense of empowerment.}

"I learned to stand up for what I believe in and not give a damn what others think of me or the consequences that might come with it. After this I felt like I can do anything I put my mind to it and be able to speak up...In the end this experience has been life changing for me and has made me see the world in a totally different perspective. I have learned so much about myself and has opened my eyes even more to the LGBT community.”

Finally, an Armenian student looks into the future and describes the kind of family she wants her newborn to grow up in as well as the kind of world she would like to be a part of.

"The pink triangle experience impacted both my life, and the lives of my children...I want to pin it on my newborn once she's out of the womb and post it on Facebook. I want everyone to see that I am not ashamed, and that I want my babies to be supporters of gay and lesbian rights. I would like to see the reactions of people, and most importantly, when she grows up I would like to talk to her and tell her that she was a part of a very important educational experience I had done for class."

After handing in her paper, this student forwarded a picture of her new born with a pink triangle on her shirt.

This paper has focused on the reactions of heterosexual students to wearing a symbol of gay rights, their increased understanding of discrimination, and their sense of responsibility for creating a fair and just environment for members of the LGBT community. The student mentioned earlier who not only expressed her anxiety about wearing the pin but also did not reveal her sexual orientation until the pin wearing began, was surprised with what she was able to gain from this experience. Her responses, as a lesbian woman, are equally important for understanding how heterosexual students can become supportive and allies in her struggle.

"Before this experience I thought that I was content and proud with my sexuality but this proved to me that I still have a long way to go...I have to have pride and make others see that my orientation is just a really small fragment of who I am...This experience was special to me as well since I, myself, am a member of the gay community and felt thrilled to stand up for what I believe in.”

The resistance and fears that our gay student had were as great as the fears that this mostly religiously conservative group of students brought to the classroom. The educator who elects to use this experience needs to believe that learning about the self and the other is a critical educational endeavor. Those who elect to use this exercise must bring neutrality, patience and understanding to the fears that most have about open-dialogue and inclusiveness. 


\section{Conclusion}

The experiences read from our students are similar to the experiences we have heard over the years when we have employed this educational endeavor. When pin-wearing was an assignment for very liberal, sophisticated students, affluent students, and diverse classrooms, the results you have read were quiet similar. Through the wearing of the Pink Triangle, students challenged themselves to think more critically about their own and other's views and biases.

They adopted a deeper understanding of the daily discrimination faced by the LGBT community, discovered ways to create safer and more inclusive environments for LGBT youth, and learned the importance of standing up for social justice.

This case study is part of a larger movement in higher education that has been referred to as transformative pedagogy. This pedagogy emphasizes the value and significance of transforming the identities that students bring to the classroom situation. These identities involve different degrees of domination and subordinations. The most frequently cited identities refer to race, gender and sexual orientation. The key work here in psychology is by Mezirow (1991; 2000) and others including Cranton (1994; 2002) and Taylor (2007). Key work has also been done in social psychology on White faculty identities (Chesler \& Young, 2013) and on student racial identities (Rabow, Venieris, \& Dhillon, 2014).

The assignment may seem foreign and alien to teachers and counselors, but we believe that if you trust your students and allow them to risk learning about themselves and others, you will be opening up a space for the students in your school and your classroom where all of the misinformation, judgment, discriminations, and prejudices can be examined. Counselors and teachers are especially important in carrying out this mission as they can practice a non-judgmental, supportive and inclusive environment that allows students to explore their fears about becoming open-minded and accepting.

We recognize that this paper does not include steps to explicitly address the " $\mathrm{B}$ " or the "T" in LGBT. However, the process of transforming identities outlined by Helms (1992) and Howard (2006), can be applied to any identities including the "B", "T" or "Q". Furthermore, the basic process of empathy, which our students achieved in this paper, is similar to the process of other identity transformations. Introducing the idea of walking in the shoes of another requires that instructors allow for choice without judgment, and allow for processing of the exercise after its completion. This is where instructors can help participants see other identities that have been treated with discrimination. This processing must also take place inside the classroom through the sharing and learning about the experiences of other classmates and not just in the final paper assignments students.

Regardless of the possible oppositions to this education endeavor, it is our hope that this paper can contribute to the efforts of educators and that they will be able to achieve what one student expressed-“... gay is just a word, pink is just a color, a rainbow is just refracted light, but it all means so much more."

\section{REFERENCES}

Chesler, M., \& Xûmena, Z. (1991). Dealing with prejudice in the classroom: The pink triangle exercise. Teaching Sociology, 19, 19-22. http://dx.doi.org/10.2307/1317848

Chesler, M., \& Young Jr., A. (2013). Faculty identities and the challenge of diversity. London: Paradigm Publishers.

Cranton, P. (1994). Understanding and promoting transformative learning. San Francisco: Jossey-Bass Publishers.

Cranton, P. (2002). Teaching for transformation. New Directions for Adult and Continuing Education, 2002, 63-72. http://dx.doi.org/10.1002/ace.50

Goffman, E. (1964). Stigma. Englewood Cliffs, NJ: Prentice Hall.

Helms, J. E. (1992). A race is a nice thing to have: A guide to being a white person or understanding the white persons in your life. Arlington, VA: Content Communications.

Howard, G. (2006). We can't teach what we don't know. New York: Teacher's College Press.

Jensen, E. (2002). The pink triangle and political consciousness: Gays, lesbians, and the memory of Nazi persecution. Journal of the History of Sexuality, 11, 319-349. http://dx.doi.org/10.1353/sex.2002.0008

Klarman, M. J. (2012). From the closet to the altar: Courts, backlash, and the struggle for same-sex marriage. OUP USA.

Mezirow, J. (2000). Learning to think like an adult: Core concepts of transformational theory. In J. Mezirow and Associates (Eds.), Learning as transformation: Critical perspectives on a theory in Progress (pp. 3-33). San Francisco, California: Jossey-Bass Inc.

Mezirow, J. (1991). Transformative dimensions of adult learning. San Francisco: Jossey-Bass Publishers.

Rabow, J., Stein, J. M., \& Conley, T. D. (1999). Teaching social justice and encountering society: The pink triangle experiment. Youth and Society, 30, 483-514. http://dx.doi.org/10.1177/0044118X99030004005

Rabow, J., Venieris, P., \& Dhillon, M. (2014). Ending racism: One microaggression at a time. Iowa: Kendall Hunt.

Taylor, E. W. (2007). An update of transformative learning theory: A critical review of the empirical research (1999-2005). International Journal of Lifelong Education, 26, 173-191. 


\section{Appendix I}

Pink Triangle Educational Exercise: Developed by Professor Jerome Rabow, UCLA, CSUN In the exercise described below, your students are being asked to wear the pink triangle.

The purpose of this classroom exercise is to have students identify with a stigmatized "other" to experience a reality that is mostly unknown to heterosexuals and to discover what their own deeper attitudes and feelings might be towards the LGBT community. The exercise challenges the self-perception of students who consider themselves "liberal" and supporters of gay rights and even advocates for LGBT rights. It is important that students be allowed to opt out of this exercise. They still can gain knowledge from other students by being exposed to their experiences of pin wearing.

For this exercise, you can ask students to make their own pink triangles in class or you can make them for students out of thick, pink construction paper. Preparing the triangle before class saves time, allowing them to make it helps demystify the pin. They should be of sufficient size as to be easily visible. The assignment for those who elect to not wear the pin involves partnering up with someone who is wearing the symbols and speaking to them daily about their experiences. It is also suggested that students all put on the pin in class together at the same time and remove them at the same time. Different types of written assignments can be developed. On the day pins are removed, we have found it useful to have all students talk about the most critical, the most awkward, the most difficult, and the most satisfying experience during their pin-wearing. It is also important to have students talk about the impact that the pinwearing had on the "self".

Writing assignments for pin-wearers and non-wearers could include the following:

\section{For Pin-Wearers}

1) Describe the most powerful moment/incident in your week of wearing the pink. Explain who, what, when, where, and most importantly, how you were feeling.

2) What was most difficult for you while wearing the pink?

3) What was most rewarding for you during this time?

4) What was the impact that this entire experience had on you?

5) Are you glad that you made this choice to wear the pin?

6) What did you learn about yourself?

For Non-Pin Wearers

1) What did you learn about the other (your pin-wearing partner)?

2) What did you learn about yourself?

3) What was most challenging in talking to the other?

4) What was most rewarding in talking to the other?

5) Do you have any regrets about your choice?

6) What was the impact of listening to your classmates share their experience? 